doi:10.17659/01.2018.0030

Journal of Case Reports 2018;8(2):112-114

\title{
Myxopapillary Ependymoma with Drop Metastasis in a Young Child
}

\author{
Athisayaraj Patrick Joshua, Murugaiyan Nagarajan, Ramesh Banu \\ Valavadi Narayanasamy Cancer Centre, G. Kuppuswamy Naidu Memorial Hospital, Coimbatore 641037, Tamil Nadu, India.
}

\section{Corresponding Author: \\ Dr. Murugaiyan Nagarajan \\ Email:mnr81@yahoo.com}

This is an Open Access article distributed under the terms of the Creative Commons Attribution License (creativecommons.org/ licenses/by/3.0).

Received : November 18, 2017

Accepted : April 4, 2018

Published : May 5, 2018

\begin{abstract}
Background: Myxopapillary ependymoma (MPE) is a rare variant of ependymoma. It has an indolent course in adults but in children it is aggressive. Because of its rarity there are no guidelines for management of metastatic MPE. Hence we report this case of MPE with drop metastasis treated with cranio-spinal irradiation (CSI) after subtotal resection (STR). Case Report: A 9 year old girl was evaluated elsewhere for low backache. MRI whole spine showed intra-dural mass compressing the conus and another lesion in the sacral spinal canal. She underwent STR. Post-operative histopathological examination was consistent with myxopapillary ependymoma. She was treated with CSI. Conclusion: Cranio spinal irradiation is essential for the treatment of metastatic MPE in pediatric population.
\end{abstract}

Keywords: Central Nervous System, Ependymoma, Low Backache, Magnetic Resonance Imaging, Spinal Canal.

\section{Introduction}

Myxopapillary ependymoma (MPE) is a rare variant of ependymoma constituting around $13 \%$ of ependymomas. These benign tumors are characterised by their slow indolent growth. It usually affects adult males in their $3^{\text {rd }}$ or $4^{\text {th }}$ decade of life. Surgery is the standard treatment of choice and adjuvant RT improves local control [1]. These tumors are rare and aggressive in children [2]. Hence we report this case of MPE in a 9 year old child.

\section{Case Report}

A 9 year old girl was initially evaluated elsewhere for complaints of sudden onset of low backache radiating to both lower limbs for two weeks. Clinically she had no neurological deficit. MRI thoracolumbar spine showed well defined enhancing intradural mass measuring $18 \times 16 \times 4 \mathrm{~mm}$ compressing the conus and proximal cauda equine nerve roots. There was another enhancing intra-dural mass within sacral spinal canal measuring $5 \times 6 \times 10 \mathrm{~mm}$ suggestive of drop metastasis and an intramedullary cystic component $10 \times 10 \times 13 \mathrm{~mm}$ in the distal thoracic spinal cord and conus [Fig.1]. There were syringomyelic changes in the mid and distal thoracic cord. She underwent T11 -L2 laminoplasty and subtotal excision of tumor. Her post-operative period was uneventful. Post-operative MRI spine showed $7 \times 6 \mathrm{~mm}$ residual disease within spinal canal at L2 level and enhancing intra-dural lesion $13 \times 8 \mathrm{~mm}$ in the spinal canal at S1-S2 level and persistent intra-medullary cystic lesion in the lower thoracic spine. She presented to our hospital for further management. Clinically she was asymptomatic with no focal neurological deficit. Slide review done in our institute was consistent with myxopapillary ependymoma and immunohistochemistry (IHC) done was positive for glial fibrillary acidic protein (GFAP) and negative for epithelial membrane antigen (EMA) [Fig. 2,3].

In view of metastatic disease at presentation and residual disease she was treated with craniospinal irradiation (CSI). She received 36 Gray (Gy) 
in 18 fractions to the entire neuraxis followed by 10.4 Gy in 6 fractions boost to the residual gross disease and metastatic lesions.

\section{Discussion}

MPE is a rare variant constituting around 13\% of ependymoma cases. It more commonly affects adults than children. Most of the spinal MPE patients present with low backache as in our case [3]. Most common sites are conus medullaris and filum terminale. Pathologically it is characterized by presence of numerous papillary projections and mucin between tumor cells [4]. In our case also the slides showed transversely cut papillary projections with core of mucin. IHC was positive for GFAP and negative for EMA which correlates with ependymoma. Though it has been classified as WHO Grade I tumor, in children it has more aggressive course.

Surgery is the mainstay of treatment and gross tumor resection is preferred. However in the Stephen et al. case series almost all paediatric MPE patients recurred after gross total resection (GTR) [5]. Hence GTR alone is not sufficient to prevent recurrence in children. Hence adjuvant treatment is warranted to prevent recurrence. Adjuvant RT plays a vital role to prevent local recurrence and also to treat disseminated disease. In our case she had disseminated disease and underwent subtotal resection. Hence she was planned for adjuvant radiotherapy.

Seven cases of MPE in less than 15 years of age treated with cranio-spinal irradiation had been reported in the literature [6-9]. Four patients had metastatic lesions in the spinal canal at the time of presentation as in our case and three patients had localized disease. Of the four patients who had metastatic disease, one had local recurrence and one patient died of unrelated cause. The remaining two patients were disease free for more than a year. CSI prevents disease recurrence and it is recommended for MPE patients with spinal metastases following tumor resection in paediatric age group. It has the

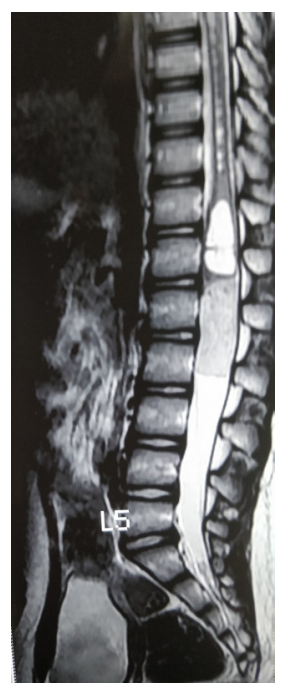

Fig.1: Sagittal section of T2 weighted image of the spine showing intra-dural mass in the lower thoracic region and another lesion in the sacral spinal canal.

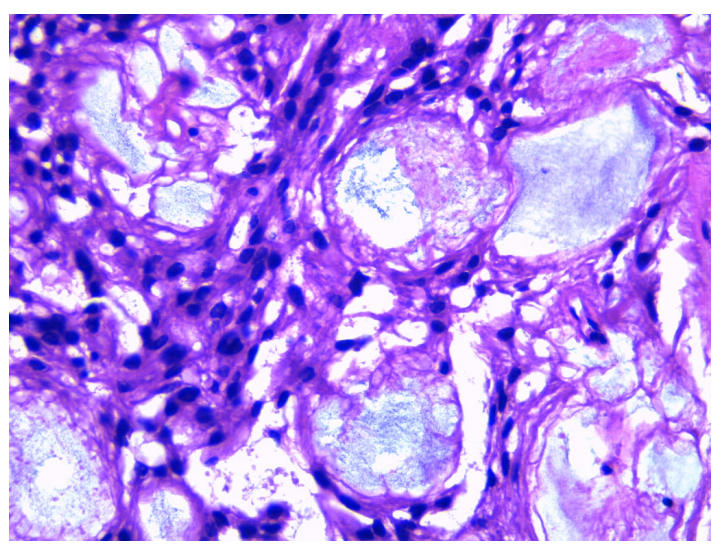

Fig.2: High power photomicrograph shows central mucin surrounded by spindle shaped cells with fibrillary cytoplasmic process.

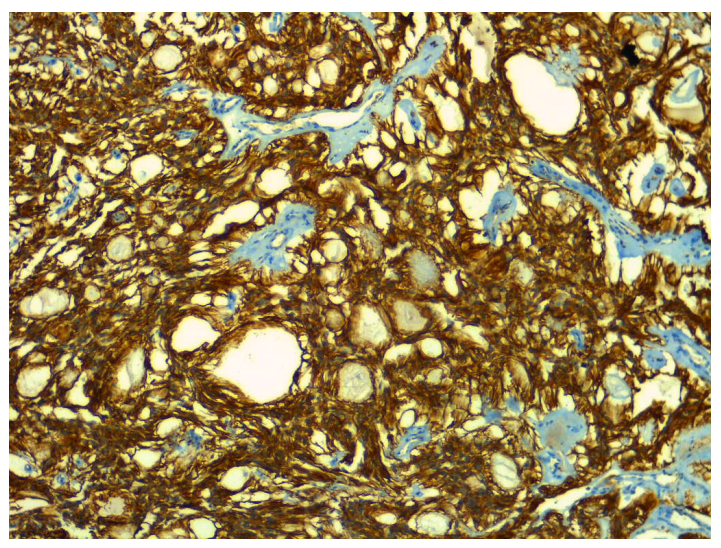

Fig.3: GFAP immunostain highlights the neoplastic ependymal cells. 
advantage of treating the disseminated disease and also it prevents recurrence.

CSI in pediatric population can cause acute and late toxicities. Tsang et al. in their retrospective study analysed the clinical outcomes and toxicities in pediatric patients who received CSI for low grade gliomas [10]. In our case during radiotherapy, the child had grade II neutropenia which was managed with granulocyte colony stimulating factor. Otherwise she tolerated treatment well. This child will be followed up for local recurrence and late toxicities.

\section{Conclusion}

Metastatic spinal MPE in children is often a clinical challenge to treat in view of local recurrence and dissemination. Adjuvant RT is indicated even after gross tumor resection to prevent local recurrence in children. CSI is warranted in patients who present with disseminated intra-spinal disease.

Contributors: APJ: literature search, data acquisition and manuscript preparation; $\mathrm{MN}$ : concept and manuscript review; RB: manuscript editing. MN will act as guarantor. All authors approved the final version of this manuscript.

Funding: None; Competing interests: None stated.

\section{References}

1. Agbahiwe HC, Wharam M, Batra S, Cohen K, Terezakis SA. Management of pediatric myxopapillary ependymoma: the role of adjuvant radiation. Int $\mathrm{J}$ Radiation Oncol Biol Phys. 2013;85:421-427.
2. Bandopadhayay P, Silvera VM, Ciarlini PD, Malkin H, Bi WL, Bergthold G, et al. Myxopapillary ependymomas in children: imaging, treatment and outcomes. J Neurooncol. 2016;126:165-174.

3. Petersen D, Lystad RP. Spinal myxopapillary ependymoma in an adult male presenting with recurrent acute low back pain: a case report. Chiropractic \& Manual Therapies. Chiropr Man Therap. 2016;24:11.

4. Wang H, Xie J. Pathological features of myxopapillary ependymomas in lumbar spinal canal: report of two cases. Int J Clin Exp Pathol. 2016;9:8736-8740.

5. Stephen JH, Sievert AJ, Madsen PJ, Judkins AR, Resnick AC, Storm PB, et al. Spinal cord ependymomas and myxopapillary ependymomas in the first 2 decades of life: a clinicopathological and immunohistochemical characterization of 19 cases. J Neurosurgery: Pediatrics. 2012;9:646-653.

6. Shirasawa H, Ishii K, Iwanami A, Mikami S, Toyama $\mathrm{Y}$, Matsumoto $\mathrm{M}$, et al. Pediatric myxopapillary ependymoma treated with subtotal resection and radiation therapy: a case report and review of the literature. Spinal Cord. 2014;52(S2):S18.

7. AlHalabi H, Montes JL, Atkinson J, Farmer JP, Freeman CR Adjuvant radiotherapy in the treatment of pediatric myxopapillary ependymomas. Pediatr Blood Cancer. 2010;55:639-643.

8. Merchant TE, Kiehna EN, Thompson SJ, Heideman RL, Sanford RA, Kun LE. Pediatric low-grade and ependymal spinal cord tumors. Pediatric Neurosurgery. 2000;32:30-36.

9. Chinn DM, Donaldson SS, Dahl GV, Wilson JD, Huhn SL, Fisher PG. Management of children with metastatic spinal myxopapillary ependymoma using craniospinal irradiation. Pediatr Blood Cancer. 2000;35:443-445.

10. Tsang DS, Murphy ES, Ezell SE, Lucas JT, Tinkle C, Merchant TE. Craniospinal irradiation for treatment of metastatic pediatric low-grade glioma. J Neurooncol. 2017;134:317-324. 